\title{
QALYs or quackery? The quagmire of quantifying the cost of breathing
}

Thomas M. Egan, MD, MSc

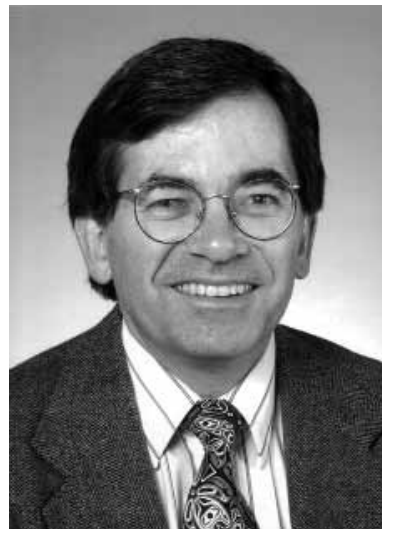

See related article on page 411 .
From the Department of Surgery, University of North Carolina at Chapel Hill, Chapel Hill, NC.

Received for publication Sept 14, 2001; accepted for publication Sept 27, 2001.

Address for reprints: Thomas M. Egan, MD, MSc, Department of Surgery, University of North Carolina at Chapel Hill, 108 BurnettWomack Building, CB 7065, Chapel Hill, NC 27599-7065.

J Thorac Cardiovasc Surg 2002;123:406-8

Copyright (c) 2002 by The American Association for Thoracic Surgery

0022-5223/2002 $\$ 35.00+0 \quad \mathbf{1 2 / 1 / 1 2 1 5 2 6}$

doi: $10.1067 / \mathrm{mtc} .2002 .121526$

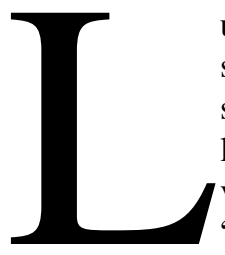

ung transplantation has become an accepted therapy to palliate endstage lung disease. Broader application is currently limited by a scarcity of suitable donors. Because it is an expensive undertaking, lung transplantation must be regularly evaluated to ensure that it provides value to society and to the patients who may benefit, because "not even the richest countries can now afford to undertake every health care activity that might conceivably do someone some good somewhere sometime."1

In this issue of the Journal, Anyanwu and associates ${ }^{2}$ present an analysis of the economic impact of lung transplantation in the United Kingdom. The study compared the costs of 677 thoracic transplantation procedures with the costs accrued by patients on the waiting list during a 4-year period. From these data Anwanyu and associates estimated the incremental cost per life-year gained and the cost per quality-adjusted life-year (QALY) gained. Studies like this often form the basis for resource allocation decisions. Caution must be exercised in extrapolating these results to different health care systems in different countries, however, and also in using this kind of information to allocate resources.

Anwanyu and associates compared the cost of transplantation with the cost of care for listed patients who had not yet undergone transplantation. However, the opportunity to transplant a given patient depends on the organ distribution algorithm in place. In the United States, lungs are distributed within geographic regions primarily according to waiting time. In the United Kingdom, thoracic organs are distributed to centers on a "rotational" system, with centers possessing considerable latitude concerning allocation to individuals on their list. It is therefore likely that as patients become more ill in the United Kingdom, they are more likely to recieve transplants and thus be removed from the list. Patients on the waiting list are therefore not an ideal group to compare costs with transplant recipients. The distribution algorithm could result in an underestimation of the costs of care for patients with end-stage lung disease; in turn, this would result in underestimation of the incremental cost of lung transplantation and undervaluing of the transplant procedure. A fundamental problem of any analysis of incremental costs of a particular therapy such as lung transplantation is the inescapable fact that death is relatively cheap. The cost of caring for patients who need a transplant but do not get one is limited by survival probability without transplantation; as an alternative to transplantation, death becomes an economic bargain.

Anwanyu and associates assumed that all listed patients were similar in healthrelated quality of life (QOL), which was estimated by a separate analysis of 87 patients awaiting lung transplantation who voluntarily answered a questionnaire. ${ }^{3}$ However, patients awaiting lung transplantation comprise a spectrum, ranging from those with minimally symptomatic pulmonary hypertension to those in an intensive care unit with an exacerbation of cystic fibrosis or chronic obstructive pulmonary disease. In our experience ${ }^{4}$ patients with cystic fibrosis awaiting lung transplantation had lower levels of anxiety and used more functional coping strategies than did 
patients with other end-stage lung disease. Similarly, transplant recipients are not a homogeneous group. Nevertheless, this study obtained utility data directly from patients who had end-stage lung disease or who had undergone lung transplantation, a method considered superior to assignment by unaffected individuals or health care providers. ${ }^{5,6}$ In fairness, there was no other suitable group to use as a control, but the additional costs that might have been incurred by patients with end-stage disease becoming more ill cannot be taken into account if they are removed from the list for transplantation.

Anwanyu and associates correctly pointed out that there is a paucity of studies addressing the cost-utility of lung transplantation. Some studies have questioned a survival benefit of lung transplantation, whereas others have shown clear survival benefit of lung transplantation for US patients with cystic fibrosis and idiopathic pulmonary fibrosis, which became apparent after 1 month for patients with cystic fibrosis and 3 months for patients with idiopathic pulmonary fibrosis. ${ }^{7}$

The implicit assumption that lung transplantation must increase life expectancy to be valuable may be flawed. If transplantation can relieve incapacitating and intolerable dyspnea, then it may be a reasonable (albeit expensive) therapy that increases QOL among survivors. With the growing disparity between donor availability and demand among lung transplant recipients, however, it may be reasonable to preferentially direct organs toward those judged more likely to die without lung transplantation. Such an algorithm for lung distribution is currently under development in the United States, and will probably be circulated for public comment by the United Network for Organ Sharing (UNOS) soon. This approach attempts to address the problem of increasing numbers of deaths among patients on the UNOS lung transplantation waiting list.

Cost-utility analysis seeks to use cost per QALY gained to guide resource allocation decisions. ${ }^{8}$ Although this is a valuable tool to understand relative costs of various therapies, it suffers from some limitations. QALY-based comparisons tend to discriminate against elderly persons, those with reduced life expectancies, and disabled persons. ${ }^{6,9}$ Because older people have a lower life expectancy than do younger people, any lifesaving therapy will understandably result in potentially higher QALY gains for younger individuals. Is there a useful concept of "age-achievable QALY?"10 Is a QALY the same value for a 20-year-old as for a 50-year-old or an 80-year-old? When asked what is was like to be 90 years old, the late comedian George Burns reportedly quipped, "It's better than the alternative!" Nord ${ }^{11}$ argues that people's interest in and entitlement to continued life may be independent of their health. Nord and colleagues wrote, "A life year gained should count as one and no less than one as long as the year is considered preferable to being dead by the person concerned." 6
In performing cost-utility analyses, economists assume that society and individuals value current utility higher than future utility. Thus, future benefits and costs are "discounted," which represents a value judgment on preference for current to future consumption. However, it is not clear that people value future health any less than current health. A higher discount rate results in less weight to future benefits. Thus, a high discount rate will favor an intervention that substantially enhances health-related QOL but has little effect on survival over one that enhances survival but has little effect on QOL, even if the QALY gains for the two interventions are identical. ${ }^{9}$ In the analysis of Anyanwu and associates, discounting at $6 \%$ per year resulted in an increase in cost per QALY of over $40 \%$ (see Table 5 in the article). $^{2}$

There are substantial differences among countries in cost of medical care. Ramsey and coworkers' pilot study ${ }^{12}$ early in the experience of the lung transplantation program in Seattle determined that the incremental cost per QALY gained through lung transplantation was $\$ 176,817$, compared with a range from $\$ 29,285$ to $\$ 48,241$ in the UK study and $\$ 71,000$ in a Dutch study. ${ }^{13}$ There are several reasons for cost differences among countries and health care systems, and there is clearly a difference in various nations' ability to pay for expensive technologies and, thus, to be able to afford "expensive" QALYs.

QALYs are not a form of quackery, but any plan to distribute health care services must take into account the fact that most people cannot stand idly by when an identified individual person's life is threatened if effective rescue measures are available. ${ }^{14}$ This "rule of rescue" poses a serious problem for resource allocation planners because of the human imperative to rescue life ${ }^{15}$ and the ethical construct of distributive justice (what we owe each other). ${ }^{14}$

By focusing on costs per QALY, we may overlook the intrinsic value of lung transplantation to our patients and society as a whole. Thus the quagmire: The fundamental problem is the assumption that there is a mathematical continuum between death and excellent health. The tool used by the investigators to measure QOL in the current study was the EuroQol EQ5D questionnaire, which allows 243 permutations of health states. A regression equation defines a utility value for these health states and, when used correctly, produces an aggregate numeric value for QOL. ${ }^{3}$ In our zeal to be objective, have we lost touch with what is important? How do we put a value on watching another sunset, hearing another song, sharing time with a loved one, or pursuing (and attaining) a lifetime dream? What is the value of a QALY? There is no concensus regarding the appropriate dollar value per QALY gained on which to base resource allocation decisions. Estimates of the value of a QALY differ widely, depending on the approach used to calculate this value, from $\$ 24,777$ to $\$ 428,286$ (median $\$ 265,345$ ). ${ }^{16}$ 
What value should we attach to being able to breathe comfortably? The quality of well-being scale has been used to measure life quality in patients with cystic fibrosis who have undergone lung transplantation. If a young adult who has never enjoyed good health enjoys 9 of the best months he or she has had in the past decade after a lung transplantation and then dies of a viral illness, what is this worth to the patient? ${ }^{17}$ To the family? To society?

We must continue to evaluate the cost-benefit and utility of our interventions, as Anyanwu and colleagues have attempted, ${ }^{2}$ because we may identify strategies to save money and make expensive therapies more economically sound. However, we must also be skeptical of efforts to make cost per QALY the sole determinant of resource allocation in health care. Life is too short, and for some breathing is too difficult.

\section{References}

1. Williams A. The role of health economics in clinical decision-making: is it ethical? Respir Med. 1991;85 Suppl B:3-5.

2. Anyanwu AC, McGuire A, Rogers CA, Murday AJ. An economic evaluation of lung transplantation. $J$ Thorac Cardiovasc Surg. 2002;123:411-20.

3. Anyanwu AC, McGuire A, Rogers CA, Murday AJ. Assessment of quality of life in lung transplantation using a simple generic tool. Thorax. 2001;56:218-22.

4. Burker EJ, Carels RA, Thompson LF, Rodgers L, Egan T. Quality of life in patients awaiting lung transplant: cystic fibrosis versus other end-stage lung diseases. Pediatr Pulmonol. 2000;30:453-60.
5. Brown GC, Sharma S, Brown MM, Garrett S. Evidence-based medicine and cost-effectiveness. J Health Care Finance. 1999;26:14-23.

6. Nord E, Pinto JL, Richardson J, Menzel P, Ubel P. Incorporating societal concerns for fairness in numerical valuations of health programmes. Health Econ. 1999;8:25-39.

7. Hosenpud JD, Bennett LE, Keck BM, Edwards EB, Novick RJ. Effect of diagnosis on survival benefit of lung transplantation for end-stage lung disease. Lancet. 1998;351:24-7.

8. Robinson R. Cost-utility analysis. BMJ. 1993;307:859-62.

9. Petrou S, Renton A. The QALY: a guide for the public health physician. Public Health. 1993;107:327-36.

10. Fryback DG, Lawrence WF. Dollars may not buy as many QALYs as we think: a problem with definig quality-of-life adjustments. Med Decis Making. 1997;17:276-84.

11. Nord E. The relevance of health state after treatment in prioritising between different patients. J Med Ethics. 1993;19:37-42.

12. Ramsey SD, Patrick DL, Albert RK, Larson EB, Wood DE, Raghu G. The cost-effectiveness of lung transplantation: a pilot study. University of Washington Medical Center Lung Transplant Study Group. Chest 1995;108:1594-601.

13. van Enckovert PJ, TenVergert EM, Bonsel GJ, Geertsma A, van-der BW, de BW et al. Technology assessment of the Dutch Lung Transplantation Program. Int J Technol Assess Health Care. 1998:14:344-56.

14. Hadorn DC. Setting health care priorities in Oregon: cost effectivness meets the rule of rescue. JAMA. 1991;265:2218-25.

15. Jonsen AR. Bentham in a box-technology assessment and health care allocation. Law Med Health Care. 1986;14:172-4.

16. Hirth RA, Chernew ME, Miller E, Fendrick AM, Weissert WG. Willingness to pay for a quality-adjusted life year: in search of a standard. Med Decis Making. 2000;20:332-42.

17. Orenstein DM, Kaplan RM. Measuring the quality of well-being in cystic fibrosis and lung transplantation: the importance of the area under the curve. Chest. 1991;100:1016-8. 